\title{
ASESSMENT OF IMAGING IN CONGENITAL INNER EAR ANOMALIES AND ITS RELATION TO COCHLEAR IMPLANTATION
}

\section{By}

\author{
Ezz El-Din M El Shiekh ${ }^{\text {a }}$ Gamal A Abdel-Maksoud ${ }^{\text {a }}$; Hassan A Wahba ${ }^{\text {b }}$ and Ibrahim M Saber ${ }^{\text {a }}$ \\ a: Otorhinolaryngology Department, Faculty of Medicine, Zagazig University \\ b: Otorhinolaryngology Department, Faculty of Medicine, Ain-Shams University
}

\begin{abstract}
Background: congenital SNHL may be caused by abnormalities of th-e membranous, or bony labyrinth. Because of improvements in imaging techniques and appearance of high resolution CT and MRI, anomalies of bony labyrinth can be diagnosed. MR imaging helps in identification of non-osseous partitioning of the malformed cochlea and identification of the neural structures contained within the internal auditory canal. The cochlear implantation has radically changed the outlook for profoundly deaf adults and children. Aim of work: to identify different types of inner ear anomalies, and to detect the percentage of patients who are amenable to cochlear implantation, and difficulties that occur during the operation. Patients and methods: This prospective study was carried out on sixty patients from 2015 till 2017 in ORL Department, Zagazig University. All patients underwent thorough preoperative evaluation especially by high resolution CT and MRI. These patients were classified according to type of diagnosed anomaly, and CI operation were done to patients who were amenable for surgery. Results: The results of this study show congenital inner ear anomalies distribution according to involved part and its percent in relation to total number 120 ears. Cochlear hypoplasia is present in 6 ears $4.5 \%$, common cavity is present in 4 ears 3\%, IP1 is present in 4 ears $3 \%$, IP2 is present in 22 ears $16.7 \%$, IP3 is present in 10 ears $7.6 \%$, posterior rotated cochlea is present in 8 ears $6.1 \%$, dilated vestibule is present in 4 ears 3\%, isolated SCC hypoplasia is present in 4 ears $3.03 \%$, SCC hypoplasia with common cavity is present in 4 ears $3.03 \%$, dysplstic SCC is present in 9 ears $6.8 \%$, dilated IAC is present in 6 ears $4.5 \%$, hypoplastic IAC is present in 24 ears $18.2 \%$, VCN hypoplasia is present in 24 ears $18.2 \%$, isolated EVA is present in 48 ears $36.4 \%$. In our study all operated cases were done through facial recess approach. Operated cases were 51 out of 66 about $77.3 \%$. Conclusion: CT and MRI are mandatory investigations for any patient prepared for cochlear implantation. Preoperative diagnosis of inner ear anomalies allows exclusion of anomalies that are considered as contraindication for CI operation.
\end{abstract}

Keywords: Cochlear implantation, Posterior tympanotomy approach, Mastoidectomy, Major complications, Minor complications

Corresponding author: Ibrahim Mohamed Saber. Tel: 01063661992, Email: ibrahimsaber25@yahoo.com

\section{INTRODUCTION}

The development of embryonic bony labyrinth occurs around 4-8 gestational weeks and the maturation of the membranous labyrinth occurs from 8 to 24 weeks. Therefore, bony labyrinth anomalies often accompany membranous labyrinth malformations ${ }^{[1]}$.

The development of imaging techniques have a great role in understanding of the ear anatomy, and diagnosis of bony anomalies of the labyrinth account for only $20 \%$ of all cases of congenital hearing loss ${ }^{[2]}$.

There are many classifications of congenital inner ear malformations, one of them was proposed by Jackler in $1987^{[3]}$, it was most widely used. He had divided bony labyrinth deformities into: labyrinth deficiency (Michel deformity), cochlear aplasia, cochlear hypoplasia, incomplete partition (Mondini dysplasia) and common cavity ${ }^{[3] .}$
Sennaroglu and Saatci $(2002)^{[4]}$ had divided bony labyrinth deformities into: Cochlear malformations include: Michel deformity, Cochlear aplasia, Common cavity, Cochlear hypoplasia, Incomplete partition type I (IP-I) and Incomplete partition type II (IP-II) (Mondini deformity).

Vestibular malformations include: Michel deformity, common cavity, absent vestibule, hypoplastic vestibule, and dilated vestibule.

Semicircular canal malformations are described as: absent, hypoplastic, or enlarged.

Internal Auditory Canal Malformations are described as: absent, narrow, or enlarged.

Vestibular and cochlear aqueduct abnormalities are described as: enlarged ${ }^{[4]}$.

Armagan et al., ${ }^{[5]}$ had described Incomplete partition type III (IP- III) ${ }^{[5]}$.

Cochlear implants have changed the thinking and approach to congenitally deaf 
children. More and more surgeons are now performing surgeries on the malformed ear, especially for malformed Cochleae ${ }^{[6]}$.

Previously, inner ear anomalies were regarded as a contraindication to cochlear implantation [7]. This was mainly due to histopathologic reports indicating decreased neural tissue in the inner ear in cases with congenital anomalies ${ }^{[8]}$.

The majority of CI operations in malformations can be done via the classical transmastoid-facial recess approach. Sometimes, the presence of complex malformations makes this approach impossible and the surgeon must be ready to modify the surgical approach ${ }^{[9] \text {. }}$

Aim of this work: Identification of different types of inner ear anomalies, and it's percentage in Egyptian patients. Preoperative detection of types of anomalies that are considered as contraindication for cochlear implantation. Detection of the percentage of patients who are amenable to cochlear implantation, and difficulties that occur during the operation. We have depended on Sennaroglu and Saatci ${ }^{[4]}$ classification.

\section{PATIENTS AND METHODS}

This prospective study was carried out on sixty patients from 2015 till 2017 in ORL Department, Zagazig.

Selection criteria:

- Patients suffer from bilateral SNHL with congenital inner ear anomalies, without measurable benefit from hearing aids over a time period of 6 months..

- No medical or psychological contra-indication for surgery.

Exclusion criteria:

- CSOM.

- Unilateral hearing loss.

- Any patient who has systemic contraindication for general anaethesia.

- Patients suffer from post meningitis cochlear ossification.

All patients in the study had done basic preoperative assessment, which include the following:

- Detailed history.
- Thorough general examination and ENT examination

- Audiological assessment

- Language assessment

- Intelligence Quotient (IQ) assessment

- Electroncephalogram (EEG)

- Imaging

Computerized tomography (CT scan) High-resolution CT of the temporal bone, followed by image reconstruction in both the axial and coronal planes. On a multidetector CT scanner, the raw axial image data set can be reconstructed with a section thickness of as little as $0.2 \mathrm{~mm}, 4000 / 200$ to obtain highquality coronal reformatted images.

Magnetic resonance imaging (MRI) the use of a 1.5- or 3-T MR imaging system is preferred for inner ear examinations, and sedation is used in most children. A thin-section gradient-echo sequence that is heavily $\mathrm{T} 2$ weighted is best suited for evaluation of the fluid-filled spaces of the membranous labyrinth and the eighth cranial nerve. A section thickness of as little as $0.4-0.7 \mathrm{~mm}$ is preferred for optimal delineation and to allow the generation of high-quality multiplanar reformatted images.

We consider vestibulocochlear nerve hypoplasia as absolute contraindication, and IPIII as relative contraindication for CI operation. All operated cases are done through classical posterior tympanotomy approach.

\section{Cases}

Case (1): incomplete partition type II (IP II) (fig 1.

Case (2): incomplete partition type I (IP I) (fig 2).

Case (3): incomplete partition type III (IP-III) (fig 3).

Case (4): common cavity (fig 4).

Case (5): enlarged vestibular aqueduct (EVA) (fig 5).

Statistical Analysis:

All data were collected, tabulated and statistically analyzed using SPSS 22.0 for windows (SPSS Inc., Chicago, IL, USA) and MedCalc 13 for windows (MedCalc Software bvba, Ostend, Belgium). Continuous variables 
were expressed as the mean \pm SD \& median (range), and the categorical variables were expressed as a number (percentage). Continuous variables were checked for normality by using Shapiro-Wilk test. Mann Whitney U test was used to two groups of nonnormally distributed variables. Percent of categorical variables were compared using Pearson's Chi-square test. All tests were two sided. p-value $<0.05$ was considered statistically significant $(\mathrm{S})$, p-value $<0.001$ was considered highly statistically significant (HS), and p-value e 0.05 was considered statistically insignificant (NS).

\section{RESULTS}

All cases (60), with RT and LT ears (120) included in this study had congenital inner ear anomalies. Radiologiocal findings are classified according to involved component of inner ear. In the following tables are divided according to its side RT ear (60), or LT ear (60), and it's percent according to total

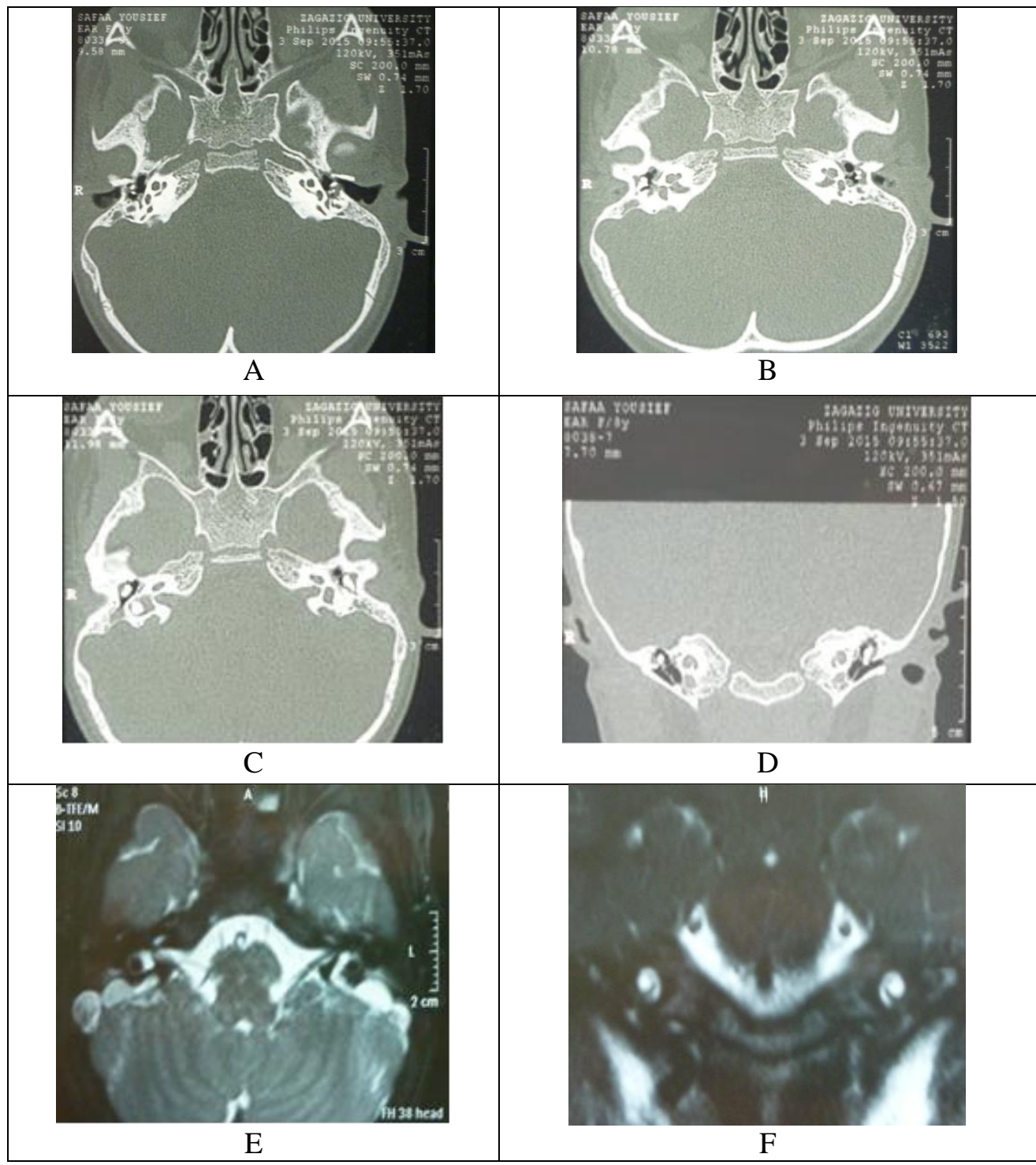

Figure (1): 5years old male with bilateral incomplete partition type II (IP-II). ( A, B, C) Axial computed tomogram (CT) of an incomplete partition type II: a cystic apex, slightly dilated vestibule and large vestibular aqueduct. (D) Coronal CT image shows the cystic cochlear apex. (E) Axial MR T2 weighted images show marked dilatation of the endolymphatic duct and sac in comparison with the normal posterior semicircular canal. The modiolus is not seen in the middle and apical turns of the cochlea. (F) Coronal MRI T2 weighted image image shows the cystic cochlear apex. 


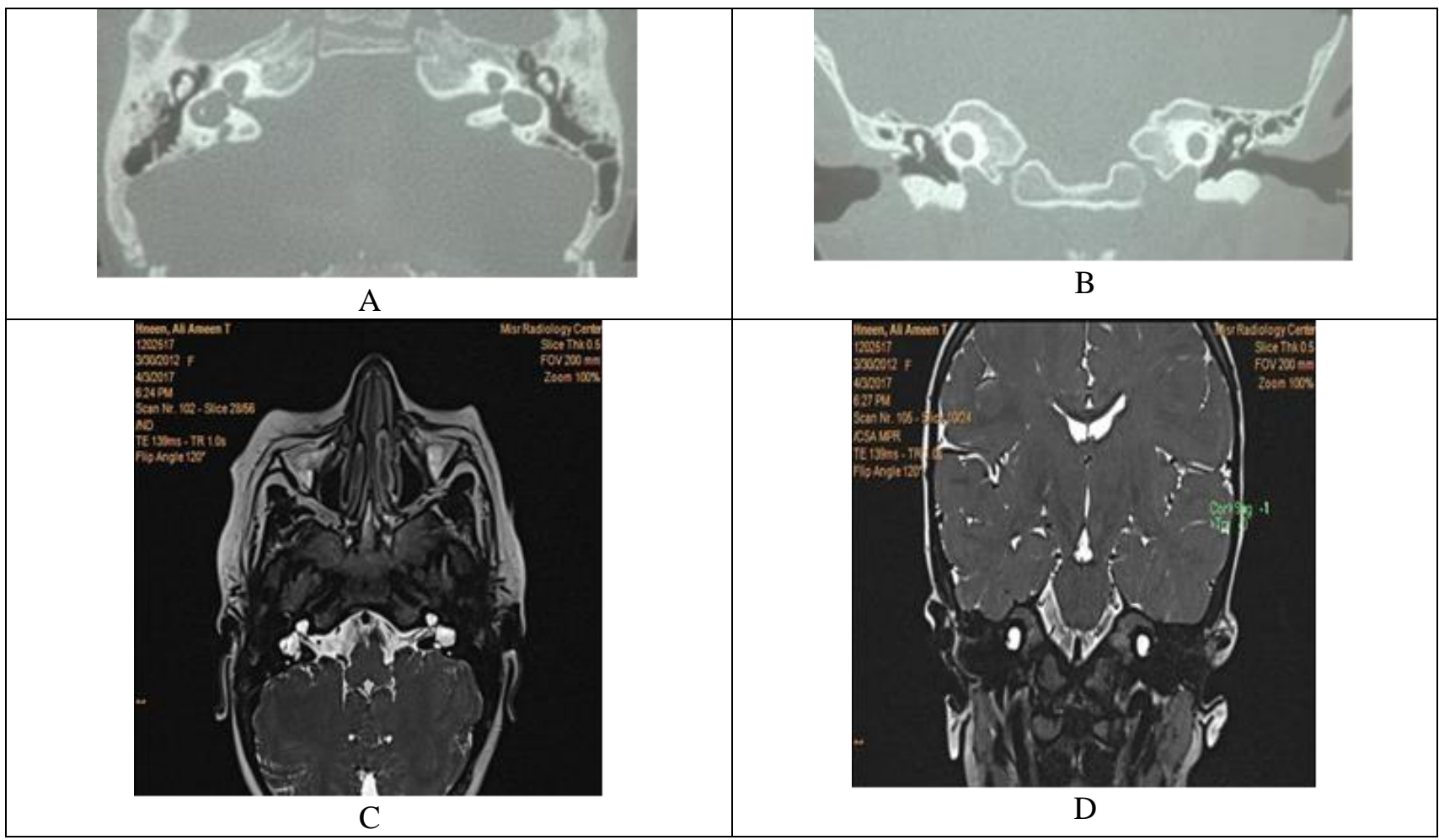

Figure (2): 5 years old male with bilateral incomplete partition type I (IP-I). (A) Axial computed tomogram (CT), (B) Coronal CT images, (C) Axial T2 weighted MRI, (D) Coronal T2 weighted MRI images of an incomplete partition type I: unpartitioned cochlea, dilated vestibule, dysplastic lateral semicircular canal and no visible EVA.

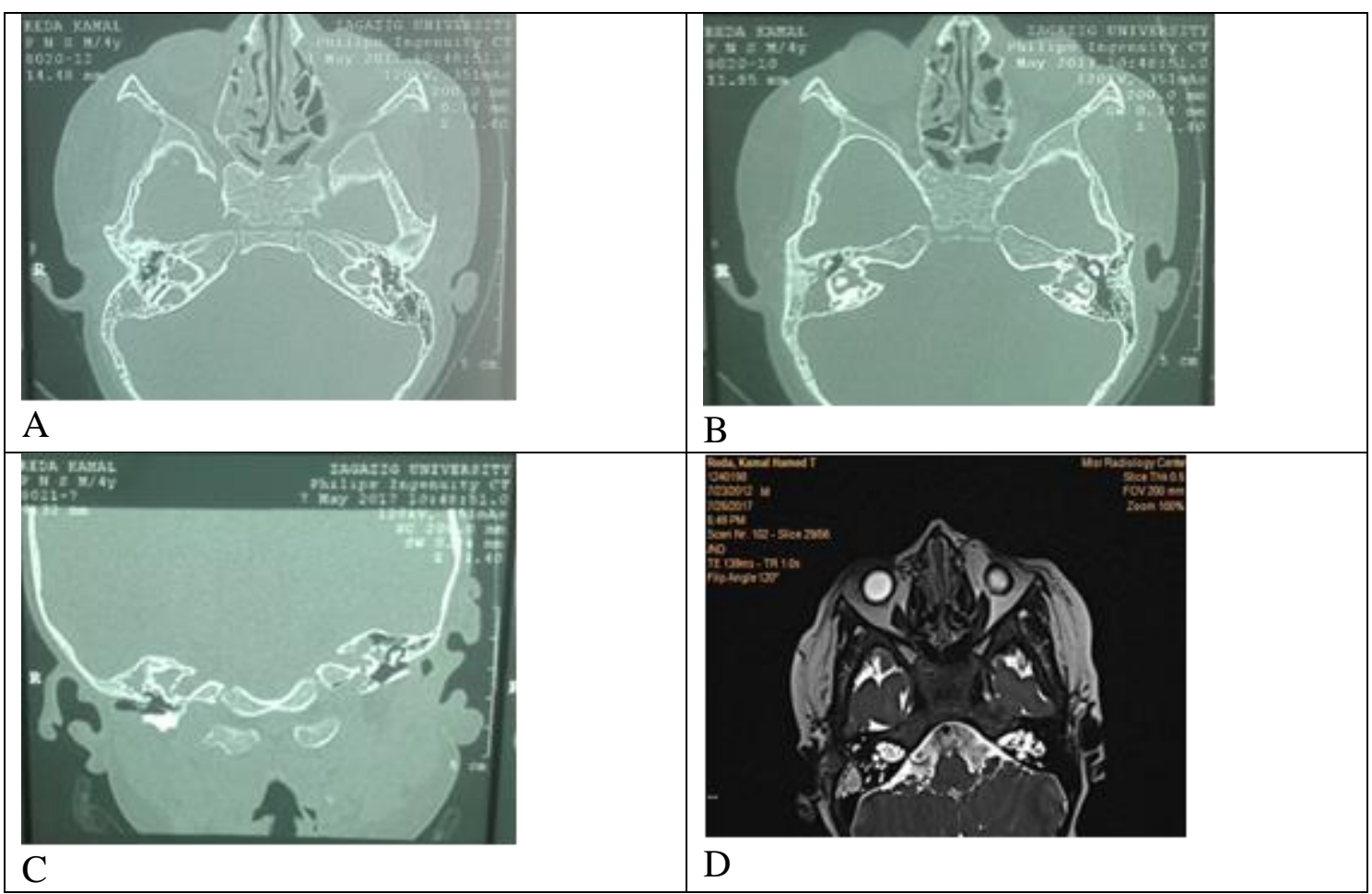

Figure (3): 4- years- old male with bilateral incomplete partition type III (IP-III). Axial and coronal CT and T2 weighted MRI show bilateral cochlear dysplasia with significantly widened cochlear aperature and incomplete bony plate between the basal turn of the cochlea and the fundus of the internal auditory canal. Morever, there is bilateral modiolus deficiency. The apical and middle turn of the cochlea are hypoplastic with incomplete partitions between two turns. Vestibule, superior and lateral SCC are dysplastic. Normal MRI appearance of vestibulocochlear nerve. 


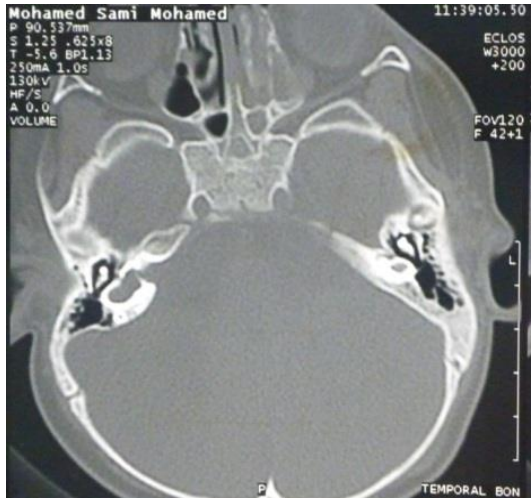

A

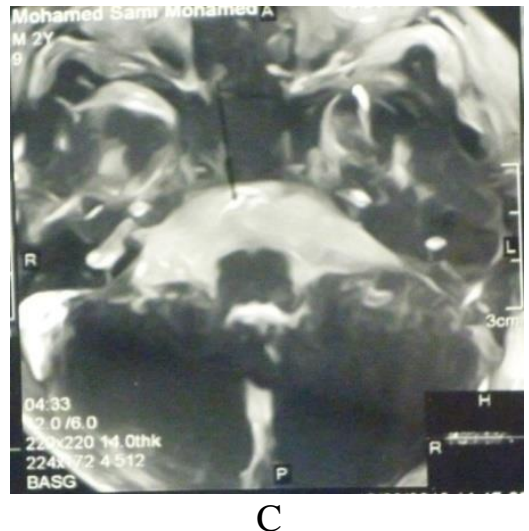

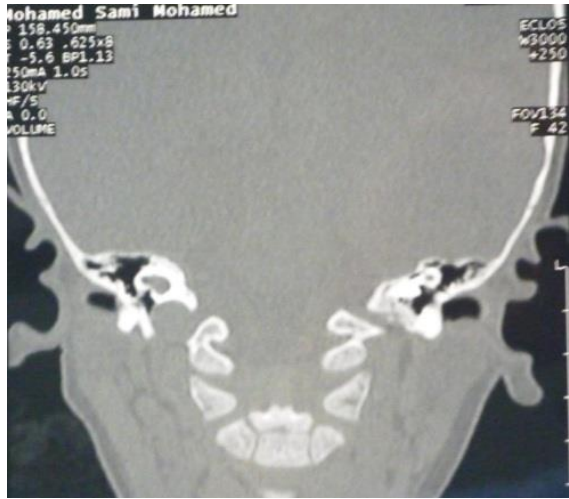

B

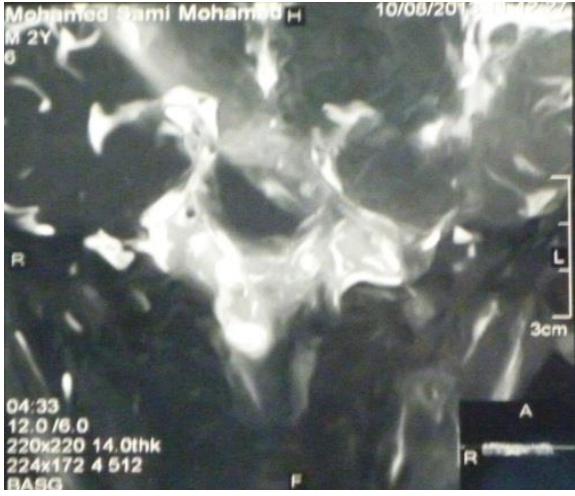

$\mathrm{D}$

Figure (4): 5 years old male with bilateral common cavity. A) Axial CT (B) Coronal CT show common cavity malformation on both sides but inner ear structure on LT side is more hypoplastic. (c) Axial T2 weighted MRI (D) Coronal T2 weighted MRI) show common cavity on both sides but LT more hypoplastic, vestibulocohlear nerve is hypoplastic on RT side and aplastic on LT side.
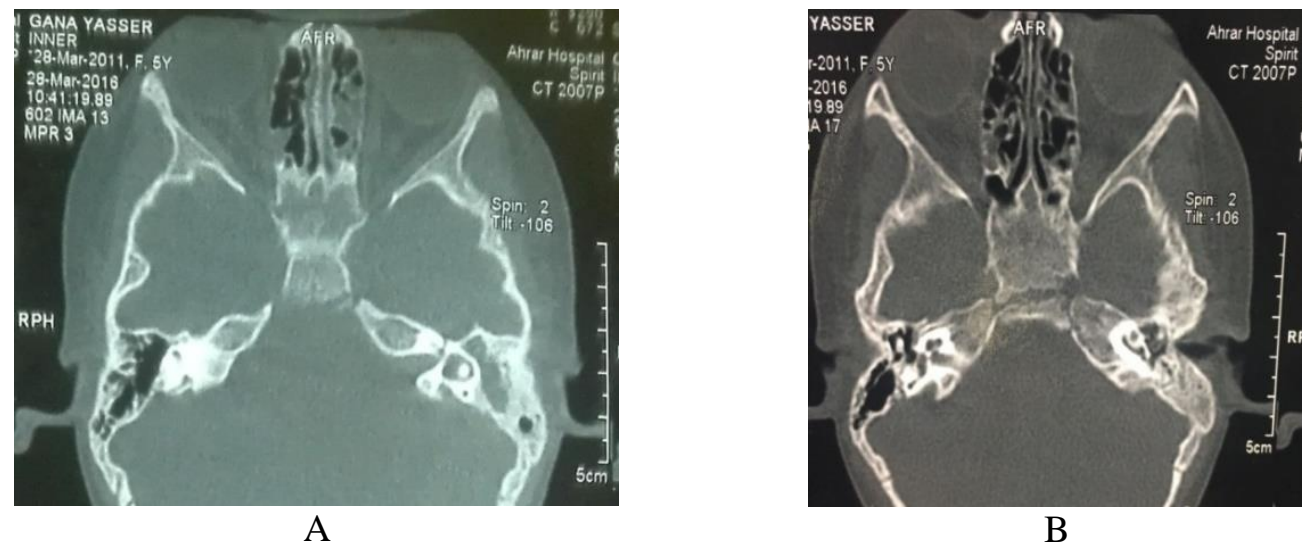

B 

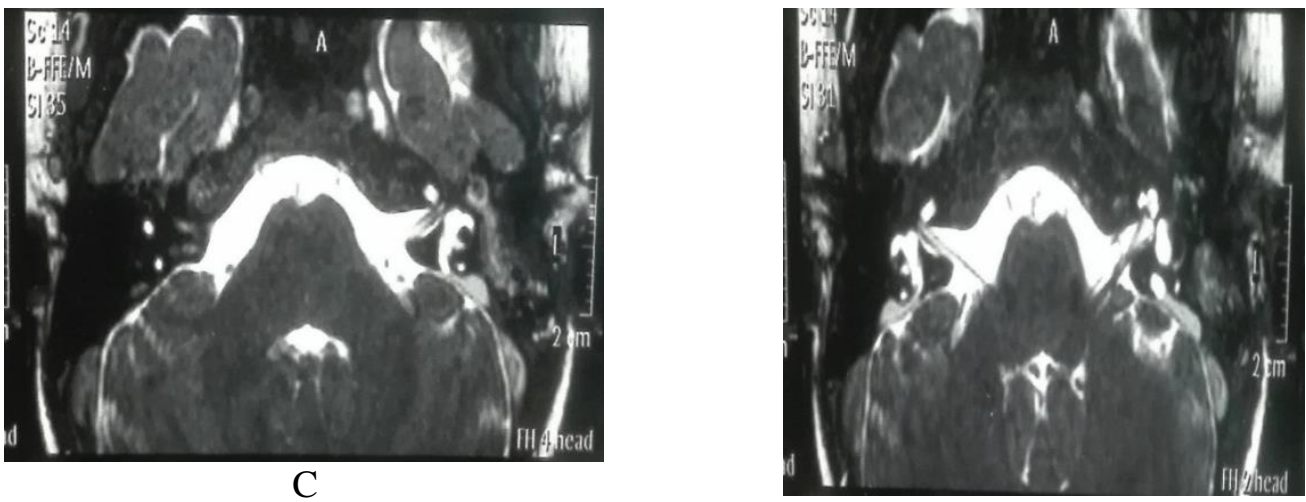

$\mathrm{D}$

Figure (5): 5 years old female with enlarged vestibular aqueduct (EVA). (A) axial CT images, (C, D) Axial T2 weighted MRI.

Table (1): Type of anomalies among the studied 60 patients (120 ears), and Factors that determine the ability to do cochlear implantation.

\begin{tabular}{|c|c|c|c|c|c|c|c|c|}
\hline & \multirow{2}{*}{\multicolumn{2}{|c|}{$\begin{array}{c}\text { All } \\
\text { ears } \\
(\mathrm{N}=120)\end{array}$}} & \multicolumn{4}{|c|}{ Implant ability } & \multirow{3}{*}{ Test } & \multirow{3}{*}{$\begin{array}{l}\mathrm{p}- \\
\text { value } \\
\text { (Sig.) }\end{array}$} \\
\hline & & & \multicolumn{2}{|c|}{$\begin{array}{c}\text { Non-implantable } \\
(\mathrm{N}=75)\end{array}$} & \multicolumn{2}{|c|}{$\begin{array}{c}\text { Implantable } \\
(\mathrm{N}=45)\end{array}$} & & \\
\hline & No. & $\%$ & No. & $\%$ & No. & $\%$ & & \\
\hline \multicolumn{9}{|l|}{ Cochlea } \\
\hline Normal & 84 & $70 \%$ & 50 & $59.5 \%$ & 34 & $40.5 \%$ & $9.409 \pm$ & \multirow{6}{*}{$\begin{array}{c}0.152 \\
\text { (NS) }\end{array}$} \\
\hline Cochlear hypoplasia & 6 & $5.0 \%$ & 5 & $83.3 \%$ & 1 & $16.7 \%$ & & \\
\hline Common cavity & 4 & $3.33 \%$ & 4 & $100 \%$ & 0 & $0 \%$ & & \\
\hline IP1 & 4 & $3.33 \%$ & 3 & $75 \%$ & 1 & $25.0 \%$ & & \\
\hline IP2 & 16 & $\begin{array}{c}13.33 \\
\%\end{array}$ & 8 & $50 \%$ & 8 & $50.0 \%$ & & \\
\hline IP3 & 6 & $5.0 \%$ & 5 & $90 \%$ & 1 & $10.0 \%$ & & \\
\hline \multicolumn{9}{|l|}{ Vestibule } \\
\hline Normal & 116 & $96.7 \%$ & 72 & $62 \%$ & 44 & $38 \%$ & \multirow[t]{3}{*}{$13.840 \pm$} & \multirow{3}{*}{$\begin{array}{l}0.086 \\
\text { (NS) }\end{array}$} \\
\hline Common cavity & 2 & $1.7 \%$ & 2 & $100 \%$ & 0 & $0 \%$ & & \\
\hline IP1 with dilated vestibule & 2 & $1.7 \%$ & 1 & $75.0 \%$ & 1 & $25.5 \%$ & & \\
\hline \multicolumn{9}{|l|}{ Semicircular canal } \\
\hline Normal & 108 & $90 \%$ & 66 & $61.1 \%$ & 42 & $38.9 \%$ & \multirow[t]{5}{*}{$13.900 \pm$} & \multirow{5}{*}{$\begin{array}{c}0.178 \\
\text { (NS) }\end{array}$} \\
\hline SCC hypoplasia & 4 & $3.33 \%$ & 3 & $75 \%$ & 1 & $25 \%$ & & \\
\hline $\begin{array}{l}\text { Common cavity with } \\
\text { SCChypoplasia }\end{array}$ & 4 & $3.33 \%$ & 4 & $100 \%$ & 0 & $0 \%$ & & \\
\hline IP1with Dysplastic SCC & 3 & $2.5 \%$ & 2 & $75 \%$ & 1 & $25 \%$ & & \\
\hline IP2with Dysplastic SCC & 1 & $0.83 \%$ & 0 & $0 \%$ & 1 & $100 \%$ & & \\
\hline \multicolumn{9}{|l|}{ IAC } \\
\hline Normal & 96 & $80 \%$ & 52 & $54.2 \%$ & 44 & $45.8 \%$ & \multirow[t]{2}{*}{$13.858 \pm$} & 0.001 \\
\hline IAC hypoplasia & 24 & $20 \%$ & 23 & $95.8 \%$ & 1 & $4.2 \%$ & & $(\mathrm{~S})$ \\
\hline \multicolumn{9}{|l|}{$\mathrm{VCN}$} \\
\hline Normal & 96 & $81.8 \%$ & 52 & $54.2 \%$ & 50 & $45.8 \%$ & \multirow[t]{2}{*}{$13.812 \pm$} & $<0.001$ \\
\hline VCN hypoplasia & 24 & $18.2 \%$ & 23 & $95.8 \%$ & 1 & $4.2 \%$ & & (HS) \\
\hline \multicolumn{9}{|l|}{ Vestibular aqueduct } \\
\hline Normal & 54 & $45.0 \%$ & 40 & $74.1 \%$ & 14 & $25.9 \%$ & \multirow[t]{2}{*}{$6.647 \pm$} & \multirow{2}{*}{$\begin{array}{c}0.010 \\
(\mathrm{~S})\end{array}$} \\
\hline EVA & 66 & $55.0 \%$ & 35 & $53 \%$ & 31 & $47 \%$ & & \\
\hline
\end{tabular}

\pm Chi-square test. Sig.: Significance.

p-value $<0.05$ is significant. 
Table (2): Implantation among the studied patients $(\mathrm{N}=60)$.

\begin{tabular}{lcc}
\hline & \multicolumn{2}{c}{$\begin{array}{c}\text { The studied patients } \\
(\mathrm{N}=60)\end{array}$} \\
\cline { 2 - 3 } Implantation & \multicolumn{2}{c}{ No. } \\
\hline Non-implantable & 15 & $25 \%$ \\
\hline Implantable & 45 & $75 \%$ \\
\hline
\end{tabular}

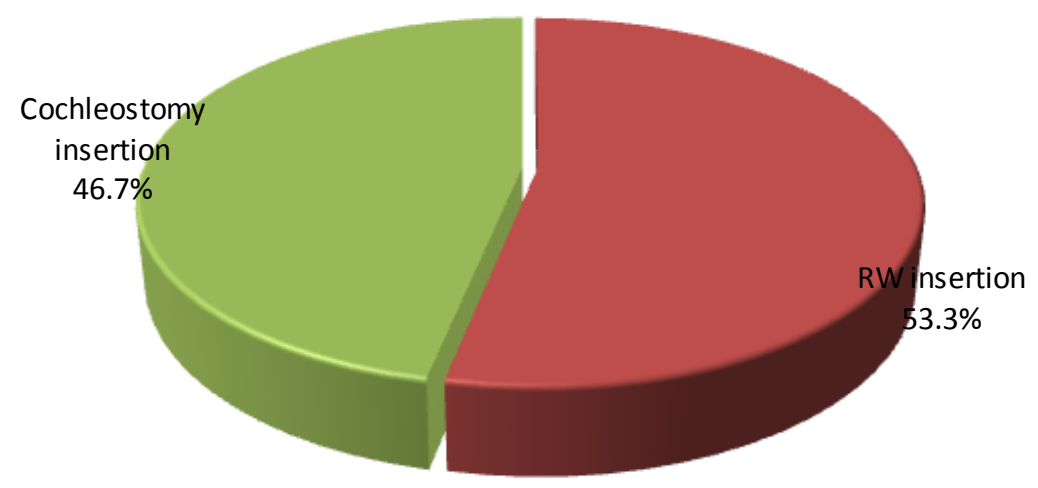

The ways of electrode insertion

Figure (14): Pie diagram shows distribution of the operated ears $(\mathrm{N}=45)$ regarding the ways of electrode insertion.

Type of the electrode
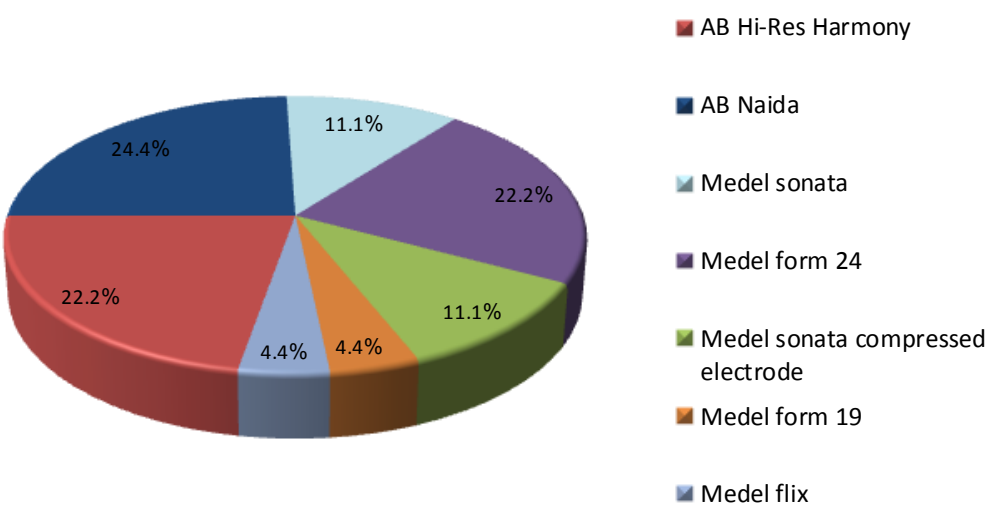

Figure (15): Pie diagram shows distribution of the operated ears $(\mathrm{N}=45)$ regarding type of the electrode.

Table (3): Presence or absence of perilymph after opening the cochlea.

\begin{tabular}{lcc}
\hline & \multicolumn{2}{c}{$\begin{array}{c}\text { The operated ears } \\
(\mathrm{N}=45)\end{array}$} \\
\cline { 2 - 3 } Implantation & No. & $\%$ \\
\hline Absent & 17 & $37.8 \%$ \\
\hline Oozing & 24 & $53.3 \%$ \\
\hline Gusher & 4 & $8.9 \%$ \\
\hline
\end{tabular}


Table (4): Complication among the operated ears $(\mathrm{N}=45)$.

The operated ears

$(\mathrm{N}=45)$

\begin{tabular}{ccc}
\cline { 2 - 3 } Complications & No. & $\%$ \\
\hline Minor complications & 20 & $44.4 \%$ \\
\hline Fever & 4 & $8.9 \%$ \\
\hline Vomiting & 18 & $40 \%$ \\
\hline Vertigo & 6 & $13.3 \%$ \\
\hline EAC stenosis & 1 & $2.2 \%$ \\
\hline Chorda tympani nerve injury & 5 & $11.1 \%$ \\
\hline Major complication & 3 & $6.7 \%$ \\
\hline CSF otorrhea & 2 & $4.4 \%$ \\
\hline FN paralysis & 1 & $2.2 \%$
\end{tabular}

\section{DISCUSSION}

The results of this study show congenital inner ear anomalies distribution according to involved part and its percent in relation to total number 120 ears. Cochlear hypoplasia is present in 6 ears 5\%, common cavity is present in 4 ears $3.33 \%$, IP1 is present in 4 ears $3.33 \%$, IP2 is present in 16 ears $13.33 \%$, IP3 is present in 6 ears $7.6 \%$, posterior rotated cochlea is present in 8 ears $5 \%$, dilated vestibule is present in 4 ears $3.33 \%$, isolated SCC hypoplasia is present in 4 ears $3.33 \%$, SCC hypoplasia with common cavity is present in 4 ears $3.33 \%$, dysplstic SCC is present in 4 ears $3.33 \%$, hypoplastic IAC is present in 24 ears $18.2 \%$, VCN hypoplasia is present in 24 ears $20 \%$, EVA is present in 66 ears $55 \%$.

So according to these results the most common congenital inner ear malformations are ordered as the following EVA, followed by hypoplastic IAC and hypoplastic VCN, then IP2. These results differ from results of Levent and Isil, 2002. ${ }^{[4]}$ Study that was done on 23 patients 64 ears, showing that order of IEMs is dilated vestibule $52 \%$, then dilated IAC $48 \%$, then EVA $35 \%$. Also these results mismatch with results of Hyun, 2006. ${ }^{[10]}$ Study which was done one 127 cases showing that EVA was the most common individual anomaly (49 cases), followed by vestibular enlargement (38 cases), other SCC dysplasia (37 cases), and shortened cochlea (34 cases).

Cochlear hypoplasia found in this study is type IV with a normal basal turn, but middle and apical turns are severely hypoplastic according to classification of Sennaroglu et al., $2015^{[11]}$.

In our study all operated cases were done through facial recess approach. Operated cases were 45 out of 66 about $75 \%$.

Only one case IP-III has been operated in this study, but there was marked C.S.F. gusher last more than $30 \mathrm{~min}$ and there was C.S.F. rhinorrhea last about 3 weeks after the operation, so we didn't operate other four cases and consider this anomaly as relative contraindication for CI, due to C.S.F. gusher and risk of meningitis pre and after the operation. This doesn't agree with Levent and Münir, 2017. ${ }^{[12]}$ Who reported that Nine primary and 1 revision incomplete partition type-III were all succesfully implanted.

We consider VCN sever hypoplasia/ aplasia diagnosed by MRI as contraindication of CI operation, but Bamiou et al., 1999. ${ }^{[13]}$ Reported that one child was considered as an inappropriate candidate for CI because of the absence of the VCN on MRI; however, the child's aided audiogram and language development suggested that some auditory fibres must be present. Acker et al., 2001. ${ }^{[14]}$ Reported a similar case and concluded that audiological response of the patient should also be taken into account before denying a CI candidacy due to absent cochlear nerve on MRI. Bradley et al., 2008. ${ }^{[15]}$ Described the outcomes in six children with hypoplastic cochlear nerves, demonstrated on MRI, who 
were selected for implantation because they had clear responses to sound with hearing aids. Their progress after two to six years of implant use were disappointing. They concluded that the benefit of cochlear implantation in this group of children is considerably restricted. This is an important point which must be discussed with the family during preoperative counseling.

We have used different types of electrodes, and during the choice of type we have depended on Sennaroglu (2010), study ${ }^{[16]}$.

In our study we found that C.S.F gusher has occurred once coclea is opened in 4 cases (8.9\%), one case IP I, 2 cases IP II, and one case IPIII. In first two cases gusher last for about 15 minutes, and in third case last more than 20 minutes. Also mild C.S.F. oozing has occurred in 24 cases (53.3), 17 cases EVA, and 7 cases IP II. While no C.S.F. leak in 17 cases (37.8\%).According to Sennaroglu et al., 2006. ${ }^{[17]}$ Study CSF gusher was encountered in four patients. Two patients had 20-minute CSF gusher and two patients had 15-minute CSF gusher. Three of these patients had IP I anomaly and one had IPIII. According to Hoffman et al., 1997. ${ }^{[18]}$ CSF gusher is reported in 40 to $50 \%$ of the patients with inner ear malformations. As reported by Au and Gibson, 1999. ${ }^{[19]}$ Profuse CSF gusher was not present in any of the patients with LVA syndrome. We have similar observation, they all had oozing.

Regarding postoperative complications, we have reported 20 cases $(44.4 \%)$ had minor complications in form of 4 cases $8.9 \%$ had fever, 18 cases $40 \%$ had vomiting, 6 cases $13.3 \%$ had vertigo, one case $2.2 \%$ had EAC stenosis, and 5 cases $11.1 \%$ had chorda tympani nerve injury. Also 3cases $6.7 \%$ had major complications in form of 2 cases $4.4 \%$ had C.S.F. otorrhea, and one case $2.2 \%$ had facial nerve paralysis.

In our study there were 5 cases $11.1 \%$ had chorda tympani nerve injury. This is matched with Hoffman and Cohen, 1995. ${ }^{[20]}$ Who reported that chorda tympani nerve injury in the classic approach was about to be $5.2 \%$ to $20 \%$ of cases.

In our study, there were 6 cases $(13.3 \%)$ had postoperative vertigo. Júnior et al., 2010. ${ }^{[21]}$ Reported 6 cases $(2.4 \%)$, out of 250 cases, had postoperative vertigo. Migirov et al., 2009. ${ }^{[22]}$ Reported 28 cases, out of 300 cases, had postoperative vertigo (10\%). Shankai et al., 2008. ${ }^{[23]}$ Reported 3 cases $(6.6 \%)$, out of 45 cases, had postoperative vertigo.

In this study C.S.F otorhea and rhinorrhea has been reported in two cases one IP II, and one case IPIII. According to Sennaroglu et al., 2006. ${ }^{[16]}$ Study there was one case IPIII had postoperative C.S.F. rhinorrhea. They recommend that when there is severe gusher during operation, it may be wise to perform CSF drainage immediately in the postoperative period.

\section{Conclusions}

CT and MRI are mandatory investigations for any patient prepared for cochlear implantation. Preoperative diagnosis of inner ear anomalies allows exclusion of anomalies that are considered as contraindication for CI operation.

Diagnosis of anomalies allows choice of the proper electrode, and the proper approach for CI operation.

In all Types of anomalies in our study, the major and minor complications of $\mathrm{CI}$ are comparable to those in the literature.

\section{REFERENCES}

1. Gulya and Schuknecht's. Anatomy of the Temporal Bone with Surgical Implications, 2007: Third Edition, by Informa Healthcare USA.

2. Park AH, Kou B, Hotaling A, et al. Clinical course of pediatric congenital inner ear malformations. Laryngoscope, 2000: 110:17159.

3. Jackler R.K, Luxford W.M, and House W.F. Congenital malformations of the inner ear: a classification based on embryogenesis. Laryngoscope, 1987: 97 (Suppl. 40), 2-14.

4. Levent Sennaroglu and Isil Saatci. A new classification for cochleovestibular malformations. Laryngoscope. December, 2000: 112: 2230-2241.

5. Armagan Incesulu, Baki Adapinar, and Cem Kecik. Cochlear implantation in cases with 
incomplete partition type III (X-linked anomaly). Eur Arch Otorhinolaryngol. 2008: 265:14251430.

6. Graham J.M, Phelps P.D, and Michaels L. Congenital malformations of the ear and cochlear implantation in children: review and temporal bone report of common cavity. Journal of Laryngology and Otology Supplement, 2000: 25: $1-14$.

7. Tucci DL, Telian SA, Zimmerman-Philips S, et al. Cochlear implantation in patients with cochlear malformations. Arch Otolaryngol Head Neck Surg. 1995: 121:833-838.

8. Monsell EM, Jackler RK, Motta G, et al. Congenital malformations of the inner ear: histologic findings in five temporal bones. Laryngoscope. 1987: 97:S18Y24.

9. Mc Elveen J.T, Carrasco V.N, Miyamoto R.T, and Linthicum F.H. Cochlear implantation in common cavity malformations using a transmastoid labyrinthotomy approach. Laryngoscope, 1997: 107:1032-1036.

10.Hyun Joon Shim, Jung-Eun Shin, Jong Woo Chung, and Kwang-Sun Lee. Inner Ear Anomalies in Cochlear Implantees: Importance of Radiologic Measurements in the Classification. Otology \& Neurotology. 2006: 27:831-837.

11.Sennaroglu L, Sennaroglu G, andOzgen B. Management of inner ear malformations. In: Sataloff RT, editor. Sataloff's comprehensive textbook of otolaryngology. JP Medical Publishers. 2015: p. 91-106.

12.Levent Sennaroglu and Münir Demir Bajin. Incomplete partition type III: A rare and difficult cochlear implant surgical indication. Auris Nasus Larynx. 2017: 2248- 2255.

13.Bamiou D.E, Savy L, O’Mahoney C, Phelps P. and Sirimanna T. Unilateral sensorineural hearing loss and its aetiology in childhood: the contribution of computerised tomography in aetiology diagnosis and management. International Journal of Pediatric Otorhinolaryngology, 1999: 51: 91-99.
14.Acker T, Mathur N.N, Savy L, and Graham J.M. Is there a functioning vestibulocochlear nerve? Cochlear implantation in a child with symmetrical auditory findings but asymmetric imaging. International Journal of Pediatric Otorhinolaryngology, 2001: 57: 171-176.

15.Bradley J, Bell M, Beale T, and Graham J.M. Variable long term outcomes from cochlear implantation in children with hypoplastic auditory nerves. Cochlear Implants International, 2008: 9: 34-60.

16. Sennaroglu L. Cochlear implantation in inner ear malformations - a review article. Cochlear Implants Int. 2010:11:4-41.

17. Sennaroglu L, Sarac S, and Ergin T. Surgical results of cochlear implantation in malformed cochlea. Otol Neurotol. 2006: 27:615-23.

18.Hoffman R.A, Downey L.L, Waltzman S.B, et al. Cochlear implantation in children with cochlear malformation. Am J Otol, 1997: 18:184- 187.

19. Au G and Gibson W. Cochlear implantation in children with large vestibular aqueduct syndrome. Am J Otol, 1999: 20:183-186.

20.Hoffman R.A and Cohen N.L. Complications of cochlear implant surgery. Ann OtoRhinoLaryngol, 1995: 166: 420-422.

21.JúniorL, Júnior $\mathrm{F}$, Calhau $\mathrm{C}$, Calhau $\mathrm{A}$, and Palhano C. postoperative Complications in implanted patients in the Cochlear Implant Program of Rio Grande do Norte- Brazil, Braz J Otorhinolaryngol, 2010: 76(4):517-21.

22.Migirov L, Dagan E, and Kronenberg J. Surgical and medical complications in different cochlear implant devices. Otoneurology, 2009: 129:741-4.

23. Shankai Yin, Zhengnong Chen, Yaqin Wu, Line Wang, Jian Zhang, Wensheng Zhou, Weidong Zhou, Jiayun Huang, Zhisen Shen, and Jian xin Qiu. Suprameatal approach for cochlear implantation in 45 Chinese children. International Journal of Pediatric Otorhinolaryngology, 2008:72: 397-403. 